International Journal of Engineering \& Technology, $7(4.34)(2018) 441-446$
International Journal of Engineering \& Technology
SPC

\title{
Dynamic Mechanical Thermal Analysis of Wood Polymer Composite Endurance to Prolonged Ultra Violet Irradiation Exposure
}

\author{
A. Shahrizan M.Z. ${ }^{1}$, Anika Zafiah M. Rus ${ }^{1}$, Nur Munirah A. ${ }^{1}$, M. Zulkhairi J. ${ }^{1}$, N. Afiqah Sufian $^{1}$, M. Saddam \\ Kamarudin $^{1}$, N. Marsi ${ }^{2}$, Siti Aida Ibrahim ${ }^{2}$, Farhana Hazwanee M.J. ${ }^{1}$, M.F.L. Abdullah ${ }^{3}$ \\ ${ }^{I}$ Sustainable Polymer Engineering, Advanced Manufacturing and Material Center (SPEN-AMMC), Faculty of Mechanical and Manufac- \\ turing Engineering (FKMP), \\ ${ }^{2}$ Faculty of Engineering Technology (FTK), Hab Pendidikan Tinggi Pagoh, 84600 Panchor, Johor, Malaysia \\ ${ }^{3}$ Department of Communication Engineering, Faculty of Electrical and Electronic Engineering, \\ Universiti Tun Hussein Onn Malaysia, 86400 Parit Raja, Batu Pahat, Johor, Malaysia \\ *Corresponding author E-mail: zafiah@uthm.edu.my
}

\begin{abstract}
This study was constructed to examine the viscoelastic properties and the microstructure of wood-plastic composites (WPCs) before and after being subjected to UV irradiation. The pellet of the wood polymer composites consists of polypropylene as the matrix and rice-husk flour as the reinforcing filler. The samples were UV irradiated from 5000 hours to 20,000 hours with the increment of 5000 hours to study the effect of weathering on the viscoelastic properties of the WPCs. The microstructures of the surface of the samples were examined using Optical Microscopy (OM). The mechanical properties of WPCs through dynamic mechanical analysis test were assessed for both polyvinyl chloride (PVC) and polypropylene (PP) samples. The value of storage modulus (E') decreases when been exposed in the ultra violet irradiation, in both glassy and rubbery states. Moreover, the density of the WPC samples is closed to light weight and result is comparable. As for morphological properties test, the surface of cracked, voids appeared at the surface of the WPC samples of both PVC and PP interface and the density of composite decreased.
\end{abstract}

Keywords: Wood polymer composites; dynamic mechanical analysis; rice husk; ultra-violet; weathering; polyvinyl chloride; polypropylene.

\section{Introduction}

A continuously growing demand for resources makes a sustainable and efficient resource utilization is more important than ever. Many existing materials rely on fossil fuels with a prospectively limited availability, which leads to an increasing competition for scarce resources. Therefore, an alternative raw material in term of demand and supply also an efficient production are required. As an alternative to materials which are based on fossil fuels, those materials made from renewable resources are promising. They help to ensure future resource allocation due to their renewable character. The processing and production of wood polymer composite (WPC) will bring the manufactured products more accessible and affordable to the consumers as an alternative to the lack of stability and non-availability of petroleum thermoplastic couple [1-2].

The usage of wood polymer composite as a material in manufacturing can result in reduction of production cost to companies and deliver greater mechanical properties to the polymeric materials. As the long term mission towards making the world to fully become environmentally friendly, all the nations must take a serious action to save the environment and ensure our future generation live in a better surrounding.

Wood polymer composite (WPC) utilization is currently growing rapidly in the construction business where it been used as an outside item of Industrial Building System (IBS). In such applica- tions, WPCs experience undesirable shading change, chalking, shrinkage and swelling, and in like manner there is need to upgrade the components in charge of the weathering of WPC and create strategies for enhancing their weathering resistance

The Dynamic Mechanical Analysis (DMA) is used to determine the response of elastic, which is important to shape recovery and also response of viscous which is essential for dispersing mechanical energy and preventing breakage to polymer. This response is called viscoelastic properties under conditions of low applied mechanical force. Polymer viscoelasticity is dependent on temperature and time.

\section{Methodology}

\subsection{Materials}

Wood polymer composite (WPCs) panels for both Polypropylene (PP) and polyvinyl chloride (PVC) were obtained from a local industry with $12 \mathrm{~mm}$ thickness, $60 \mathrm{~cm}$ width and $3 \mathrm{~m}$ length. Both $\mathrm{PP}$ and PVC panels were manufactured by an extrusion method with standard composition ratio of polymer to rice husk (RH) of 70:30 weight percentage ration (wt\%), thus can improve and reassure the homogeneity of the WPC board [7]. 


\subsection{Preparation of WPC Sample}

Wood polymer composite (WPCs) panels were used to prepare a rectangular specimen having size $30 \mathrm{~mm} \times 4 \mathrm{~mm} \times 2 \mathrm{~mm}$ and 10 $\mathrm{mm} \times 10 \mathrm{~mm} \times 10 \mathrm{~mm}$ for the dynamic mechanical analysis experiment and density test respectively. Sample preparation sizes for the physical and mechanical tests are listed on Table 1.

Table 1: Parameter for the physical and mechanical tests

\begin{tabular}{|c|c|c|}
\hline Types of Test & Dynamic Mechanical Analysis Test & Density Test \\
\hline Apparatus & TA Instrument Q800 & HR-250AZ \\
\hline Length & $30 \mathrm{~mm}$ & $10 \mathrm{~mm}$ \\
\hline Width & $4 \mathrm{~mm}$ & $10 \mathrm{~mm}$ \\
\hline Thickness & $2 \mathrm{~mm}$ & $10 \mathrm{~mm}$ \\
\hline
\end{tabular}

\subsection{Dynamic Mechanical Analysis}

Dynamic mechanical analyser (DMA) is a sensitive technique that employed to characterize the mechanical response of materials by monitoring properties changes in a material with regard to the temperatures and frequencies.

The DMA test was performed using TA Instrument Q800 located at MINT-SRC, University of Tun Hussein Onn Malaysia (UTHM). WPCs specimens were scanned over a range of temperatures of $20^{\circ} \mathrm{C}-150^{\circ} \mathrm{C}$. The oscillation frequency was performed at $1 \mathrm{~Hz}$ ramped at $3^{\circ} \mathrm{C} / \mathrm{min}$ to $150^{\circ} \mathrm{C}$ according to ASTM D7031 (Standard Guide for Evaluating Mechanical and Physical Properties of Wood-Plastic Composite Products). The storage modulus, loss modulus and mechanical factor $(\tan \delta)$ were recorded and plotted against temperature.

\subsection{Density Test}

The density tests were used to determine the density of a solid sample. Density values can be derived by the ratio of mass per volume. The density test is based on the principle of Archimedes of weight loss during immersion in fluid equal to the weight of the fluid displaced. Furthermore, the density of the solid is determined with the help of a metallic liquid such distilled water or ethanol. Density test model HR-250AZ was employed to determine its density of WPC sample.

By averaging the measured values, the densities of a solid were obtained. The measurement been started when water temperature became stable. The 'Re-Zero' key were pressed to set the displayed value to zero. The sample were placed on the upper pan in air and the value A was recorded. Then, the sample were placed on the lower pan in liquid and the value B is recorded. Lastly, the depths were kept approximately $10 \mathrm{~mm}$ under liquid surface.

\subsection{Optical Microscopy (OM)}

The Optical Microscope Nikon Eclipse LV150N is located at Material Science and Material Characterization Laboratory been employed to study the morphological surface of WPC samples.

The fine focus knob is used when the samples were near the objective lens. Then, the image is cantered and the light is adjusted using the diaphragm. After that, the objective lenses are now switched to the highest power objective lens $100 \mu \mathrm{m}$. The fine focus is read and light (diaphragm) as needed.

\subsection{Accelerated Weathering Tests of WPC}

The UV light irradiation on the specimens was conducted by using the UV Accelerated Weatherometer Haida International Equipment Ltd. The UV accelerated weathering test was carried out according to the ASTM D 4587, which is a standard practice for light/water exposure of paint. The UV weatherometer consists of fluorescent lamps that emit light ranging from 280 to $320 \mathrm{~nm}$ with a tail extending tending to $400 \mathrm{~nm}$.
The procedures to start the process of ' $\mathrm{UV}$ accelerated weathering tester' are the distilled water was filled up to $90 \%$ into the water tank that located at the left side of the UV accelerated weathering tester. After that, the UV accelerated weathering tester power button was switched to 'ON'. The sample were mounted on the sample holder/rack and inserted in the UV weatherometer. Lastly, the data were inserted into the program setting at the screen UV accelerated weathering tester to 5000 hours up to 20,000 hours with the increment of 5000 hours.

\section{Results and Discussion}

\subsection{Dynamic Mechanical Analysis}

Dynamic parameters such as storage modulus (E'), loss modulus (E'), and loss factor $(\tan \delta$ ) are temperature-dependent and provide information about interfacial bonding between the reinforced filler and polymer matrix of composite material.

These parameters can reflect the motion state inside the composites and are important to the efficient use of fiber-reinforced polymer composites, which are widely used in WPC.

The cross-linked density (Ve) of a cross-linked polymer can be obtained from the rubbery modulus by using Equation (1), based on the rubber elasticity.

$\mathrm{E}^{\prime}=3 \mathrm{Ve} \mathrm{RT}$

$\mathrm{E}^{\prime}$ is the storage modulus in the rubbery plateau above $\mathrm{Tg}$ (ca. $\mathrm{Tg}$ $\left.+/-25^{\circ} \mathrm{C}\right), \mathrm{R}$ is the gas constant $\left(8.314 \mathrm{JK}^{-1} \mathrm{~mol}^{-1}\right)$ and $\mathrm{T}$ is the temperature in Kelvin.

3.1.1. Dynamic Mechanical Analysis of WPC Samples (Polyvinyl Chloride)

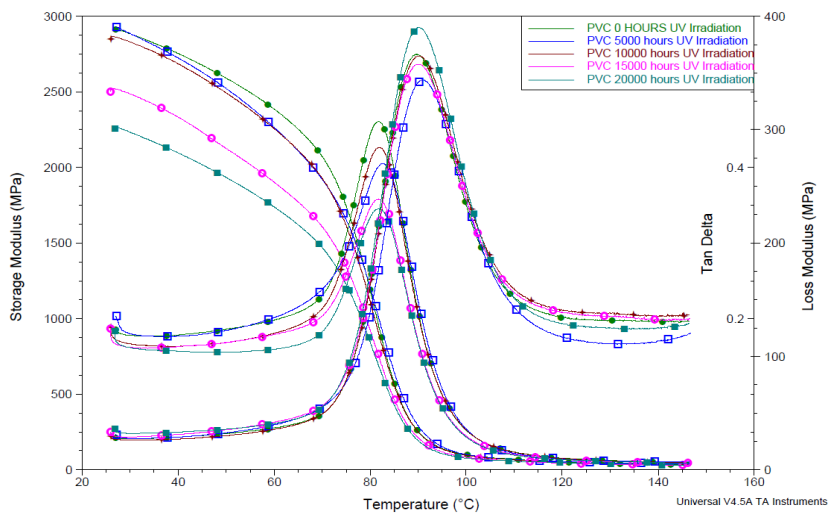

Fig. 1: Overlay of Storage Modulus, Loss Modulus, Tan $\delta$ of Polyviny Chloride against temperature

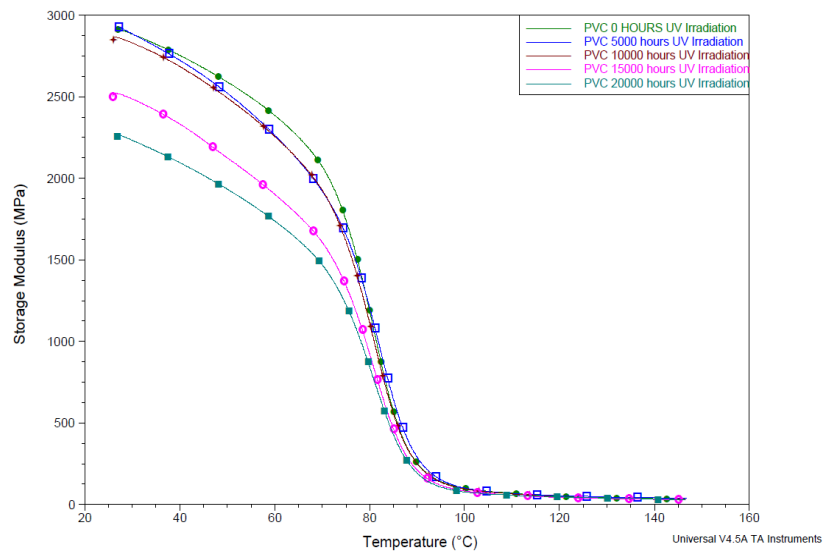

Fig. 2: Overlay of Storage Modulus of Polyvinyl Chloride against temperature 


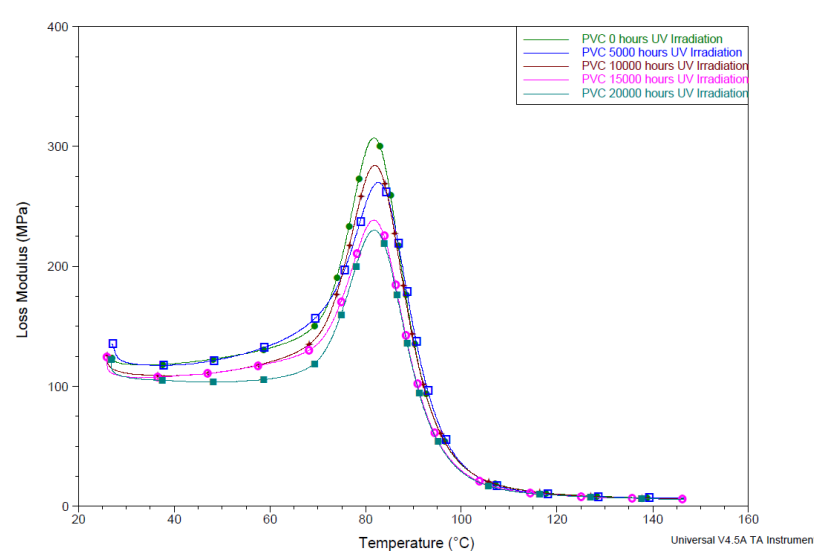

Fig. 3: Overlay of Loss Modulus of Polyvinyl Chloride against temperature

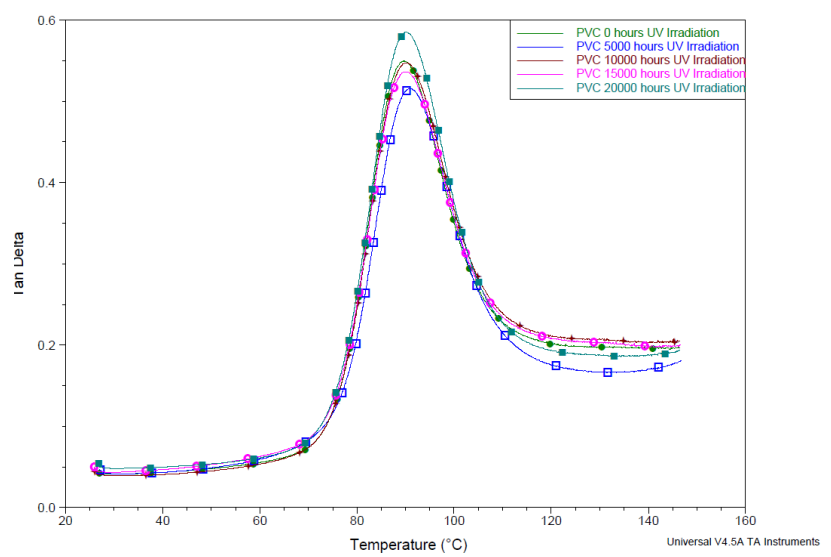

Fig. 4: Overlay of Tan Delta of Polyvinyl Chloride against temperature

Table 2: Effect of Tg, Tan $\delta$ max, storage modulus upon UV Irradiation Exposure of Polyvinyl Chloride

\begin{tabular}{|c|c|c|c|}
\hline $\begin{array}{c}\text { Parameter } \\
\text { PVC }\end{array}$ & $\operatorname{Tg}\left({ }^{\circ} \mathrm{C}\right)$ & $(\operatorname{Tan} \delta)_{\max }$ & $\begin{array}{c}\text { Storage } \\
\text { Modulus } \\
\left(\mathrm{E}^{\prime}, \mathrm{MPa}\right)\end{array}$ \\
\hline $\begin{array}{c}\text { Sample 1 } \\
\text { 0 Hours }\end{array}$ & 89.56 & 0.5499 & 59.3633 \\
\hline $\begin{array}{c}\text { Sample 2 } \\
\text { 5000 Hours }\end{array}$ & 91.02 & 0.5160 & 58.5808 \\
\hline $\begin{array}{c}\text { Sample 3 } \\
\text { 10000 Hours }\end{array}$ & 90.26 & 0.5476 & 54.2777 \\
\hline $\begin{array}{c}\text { Sample 4 } \\
\text { 15000 Hours }\end{array}$ & 90.16 & 0.5366 & 49.2897 \\
\hline $\begin{array}{c}\text { Sample 5 } \\
\text { 20000 Hours }\end{array}$ & 90.13 & 0.5850 & 51.1285 \\
\hline
\end{tabular}

The viscoelasticity is described quantitatively by the storage modulus (E'), loss modulus (E') and damping factor $(\tan \delta)$. The E' indicates the elastic behaviour (stiffness) of the polymer and describes the ability to instantaneously strain (i.e., deform) and recovery when stressed and released, respectively. In contrast, the E" indicates the energy converted into heat and can thus be used as a measurement of viscous component or unrecoverable oscillation energy dissipated per cycle.

Finally, the $\tan \delta$ is the ratio of E" to E' and describes the relative level of viscosity to elasticity where an ideal elastic material is zero and an ideal viscous fluid would be infinite.

From Figure 2, it can be easily seen that the value of storage modulus (E') decreases when been exposed in the ultra violet irradiation, in both glassy and rubbery states. The highest value of storage modulus is $59.3633 \mathrm{MPa}$ for the un-irradiated sample at 0 hours ultra violet exposure with the value of crosslink density of $6.5646 \mathrm{M} / \mathrm{m}^{3}$.

The storage modulus of the WPC samples from the un-irradiated to the ultra violet irradiation exposure from 5000 hours to the 20,000 hours were displaced downwards indicating that the expo- sure to the ultraviolet led to drop in storage modulus significantly. The storage modulus is proportional to the peak energy stored in the sample as a measure of its viscoelasticity.

Chain breakages (degradation) are associated with a decrease in energy storage capacity recorded in the decrease of storage modulus [9-10]. This loss of storage modulus and hence the viscosity of the material, makes the material brittle with subsequent breakage on the application of external force [11-12]

Material will change from rigid to the elastic state with the movement of small groups and the chains of molecules within the polymer structure. In fibre reinforced composite, damping is affected by the presence of fibres. From the Figure 3, it can be observed that the maximum value of loss modulus (E') for the WPC samples for un-irradiated sample is higher than the samples that been ultra violet exposed until 20,000 hours. These results may be attributed to the interfacial interaction between the polyvinyl chloride as its polymer, and also the rice husk content as the filler in this wood polymer composites sample reacted with the irradiation of the ultra violet exposure.

From Figure 4, it is very evident that the glass transition temperature $\mathrm{Tg}$, determined by the value of $\tan \delta$ peak maximum. The highest value of $\tan \delta$ is 0.5850 for the sample of 20,000 hours ultra violet irradiation exposure. However, the results of DMA measurements in this work have some differences with those previously reported. It may be attributed to different processing condition of sample and the aspect ratio of the polymer composition with the filler and type of the filler.

\subsubsection{Dynamic Mechanical Analysis of WPC Samples (Poly- propylene)}

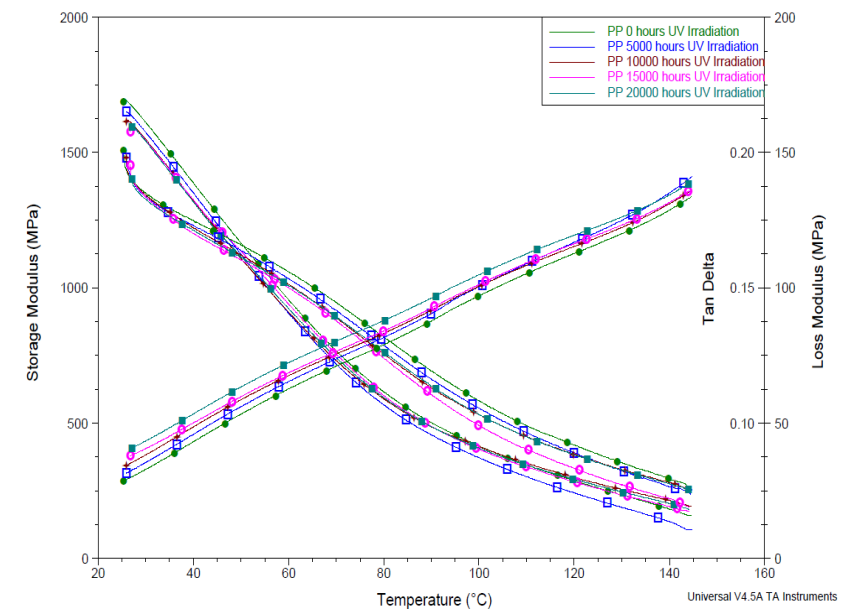

Fig. 5: Overlay of Storage Modulus, Loss Modulus, Tan $\delta$ of Polypropylene against temperature

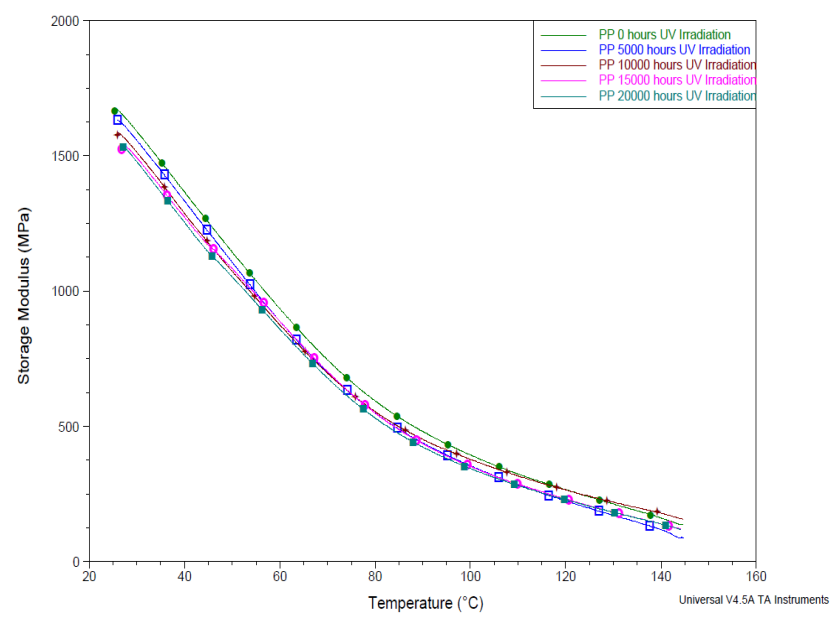

Fig. 6: Overlay of Storage Modulus of Polypropylene against temperature 


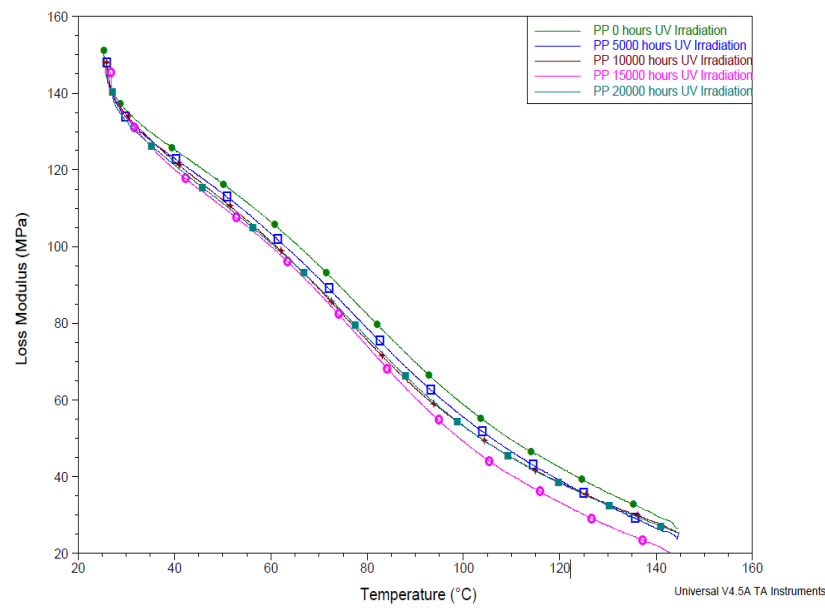

Fig. 7: Overlay of Loss Modulus of Polypropylene against temperature

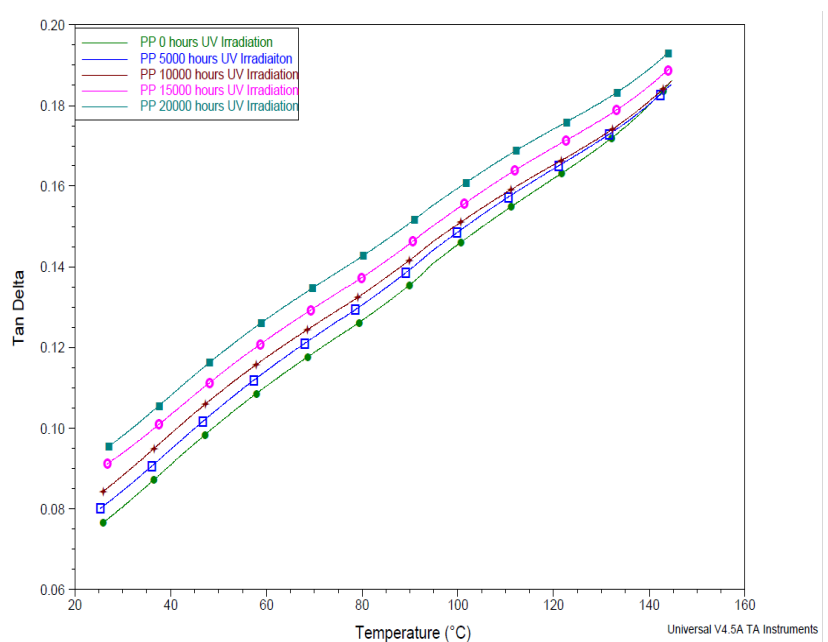

Fig. 8: Overlay of Tan Delta of Polypropylene against temperature

Table 3: Effect of Tg, Tan $\delta$ max, storage modulus and cross-linked density upon UV Irradiation Exposure of Polypropylene

\begin{tabular}{|c|c|c|c|}
\hline & $\operatorname{Tg}\left({ }^{\circ} \mathrm{C}\right)$ & $(\operatorname{Tan} \delta)_{\max }$ & $\begin{array}{c}\text { Storage } \\
\text { Modulus } \\
(\mathrm{E},, \mathrm{MPa})\end{array}$ \\
\hline $\begin{array}{c}\text { Parameter } \\
\text { Sample 1 } \\
\text { 0 Hours }\end{array}$ & 107.7847 & 0.1521 & 199.0370 \\
\hline $\begin{array}{c}\text { Sample 2 } \\
5000 \text { Hours }\end{array}$ & 107.3744 & 0.1512 & 197.6590 \\
\hline $\begin{array}{c}\text { Sample 3 } \\
\text { 10000 Hours }\end{array}$ & 99.8664 & 0.1497 & 193.3724 \\
\hline $\begin{array}{c}\text { Sample 4 } \\
15000 \text { Hours }\end{array}$ & 100.5681 & 0.1514 & 189.1426 \\
\hline $\begin{array}{c}\text { Sample 5 } \\
\text { 20000 Hours }\end{array}$ & 104.4532 & 0.1499 & 184.4429 \\
\hline
\end{tabular}

From Figure 6, the value of storage modulus (E') of the WPC samples of polypropylene also decreases when been exposed in the ultra violet irradiation, in both glassy and rubbery states. The highest value of storage modulus is $199.0370 \mathrm{MPa}$ for the unirradiated sample at 0 hours ultra violet exposure with the value of crosslink density of $20.957 \mathrm{M} / \mathrm{m}^{3}$.

The storage modulus of the WPC samples from the un-irradiated to the ultra violet irradiation exposure from 5000 hours to the 20,000 hours were displaced downwards indicating that the exposure to the ultraviolet led to drop in storage modulus significantly. The storage modulus is proportional to the peak energy stored in the sample as a measure of its viscoelasticity.

This loss of storage modulus and hence the viscosity of the material, makes the material brittle with subsequent breakage on the application of external force [13].

From Figure 7, it can be observed that the maximum value of loss modulus (E") for the WPC samples for un-irradiated sample is higher than the samples that been ultra violet exposed until 20,000 hours. These results may be attributed to the interfacial interaction between the polypropylene as its polymer and also the rice husk content as the filler in this wood polymer composites sample reacted with the irradiation of the ultra violet exposure.

From Figure 8, it is very evident that the glass transition temperature $\mathrm{Tg}$, determined by the value of $\tan \delta$ peak maximum. The low-temperature peak is related to the glass-rubber transition of the amorphous polymer fractions and is taken as the glass transition temperature $(\mathrm{Tg})$.

The highest value of $\tan \delta$ is 0.1521 for the un-irradiated WPC sample or 0 hours ultra violet irradiation exposure. By previous studies, it was reported that damping in the transition part is actually measurement of imperfection in elasticity and energy used to deform the material was dissipated into heat. Thus, leads to the reduction in friction of intermolecular chain with the present of reinforcement [14].

\subsubsection{Cross-Linked Density of Wood Polymer Composite (WPC) upon UV Irradiation Exposure}

In general, the properties of thermoplastics for special applications by cross linking density are modified by using different methods. The melt flow index of the cross linking was reduced, crystallinity, modulus young and elongation at break, it improves the impact strength, creep resistance, resistance to slow crack growth and also environmental stress crack resistance.

The effect of crosslinking on the various regions of the DMA curve is visible in rubbery and glass transition region. From Figure 9 , it can be observed that the maximum value of cross-linked density polyvinyl chloride and polypropylene $6.56 \mathrm{M} / \mathrm{m}^{3} \times 10^{3}$ and $20.96 \mathrm{M} / \mathrm{m}^{3} \times 10^{3}$ respectively. However, both samples show a similar behaviour as UV irradiation were increased, the crosslinked density tend to decreased accordingly.

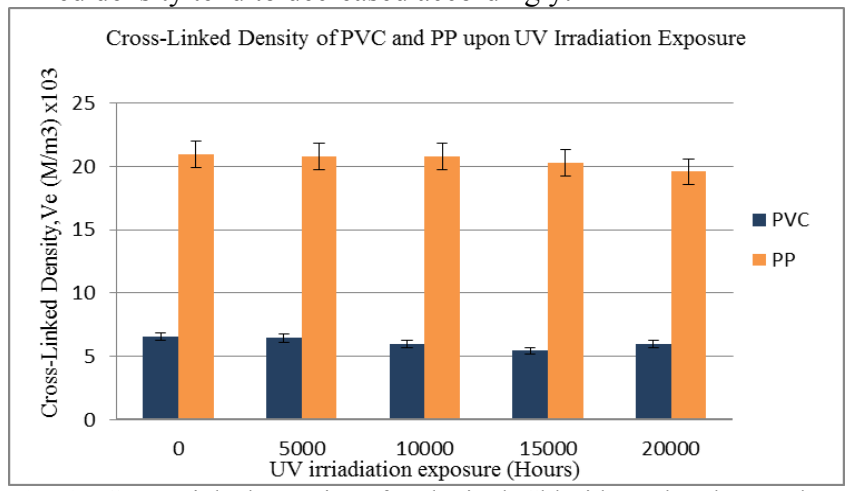

Fig. 9: Cross-Linked Density of Polyvinyl Chloride and Polypropylene upon UV Irradiation Exposure

\subsection{Density Test}

Density test are carried out by using Density Test Model HR$250 \mathrm{Az}$ for the WPC samples that undergo UV irradiation exposure The measurement is in $\mathrm{g} / \mathrm{cm}^{3}$ referring to the machine scale. The result findings are compared between different types of WPC samples based on the UV irradiation exposure against density. The average value of the sample is tabulated in the Table 4 .

Table 4: Density test result for the WPC samples (Polyvinyl Chloride) and (Polypropylene)

\begin{tabular}{|c|c|c|}
\hline $\begin{array}{c}\text { UV Irradiation } \\
\text { Exposure (Hours) }\end{array}$ & $\begin{array}{c}\text { PVC Density } \\
\left(\mathrm{g} / \mathrm{cm}^{3}\right)\end{array}$ & $\begin{array}{c}\text { PP Density } \\
\left(\mathrm{g} / \mathrm{cm}^{3}\right)\end{array}$ \\
\hline 0 & 1.3929 & 1.1270 \\
\hline 5000 & 1.3812 & 1.1151 \\
\hline 10000 & 1.3759 & 1.1117 \\
\hline 15000 & 1.3745 & 1.0083 \\
\hline 20000 & 1.3690 & 1.0032 \\
\hline
\end{tabular}

Table 4 shows that as UV irradiation were increased, the density tend to decrease accordingly. For the density result of WPCs sam- 
ples (Polyvinyl Chloride) starts from the initial highest density at $1.3929 \mathrm{~g} / \mathrm{cm}^{3}$ until the lowest density value of $1.3690 \mathrm{~g} / \mathrm{cm}^{3}$. The total percentages reduction in density of the WPCs samples (Polyvinyl Chloride) is $1.72 \%$ from un-irradiated samples to the 20,000 hours UV irradiation exposure.

Then, for the density result of WPCs samples (Polypropylene) starts from the initial highest density at $1.1270 \mathrm{~g} / \mathrm{cm}^{3}$ and decreased until the lowest density value of $1.0032 \mathrm{~g} / \mathrm{cm}^{3}$. For the total percentages reduction in density of the WPCs samples (Polypropylene) is $10.98 \%$ from un-irradiated samples to the 20,000 hours UV irradiation exposure.

Due to the properties of the natural lignocellulose material which are low densities compared to traditional mineral fillers, it has attracted the attention of scientists and engineers for using as fillers in polymer composites. Natural fibres usually have the density between 1.1 to $1.5 \mathrm{~g} / \mathrm{cm}^{3}$ in a solid form and affect the density of the composites [21-22].

Density of WPCs specimen was decreased due to volatile matter reduces during the UV irradiation exposure. The influence also came from the crosslink density of the polymer molecule. From Table 2 shows the density of both of the WPC samples had no drastic change neither before nor after prolongs UV irradiation exposure. Hence, this shows that the UV irradiation exposure does affect the density of the samples.

\subsection{Morphological Properties Testing Result of WPC Samples}

Morphological properties test is also being performed in this research to overcome some significant barrier, and also to obtain better understanding of the composite performance and the internal bond of the WPC samples. The morphological image been captured by using an Optical Microscope at Material Science Laboratory at UTHM.

The WPC samples (Polyvinyl Chloride and Polypropylene) that been ultra violet irradiated from 5000 hours until 20,000 hours placed on the stage of the microscope and the power objective lens of $50 \mu \mathrm{m}$ and $100 \mu \mathrm{m}$ been selected. The lenses were raised using the coarse focus knob until see the image come into focus and then go out again, then focus back until obtained the centre focus.

After the WPC samples were undergoing an ultra violet irradiation exposure from 5000 hours until 20,000 hours, the surface morphology of the composites had changed drastically.

After exposure, the density of the WPC samples decreased. This is consistent with the surface degradation (surface cracks and voids) obtained by the Optical Microscopy from the 5000 hours until 20,000 hours ultra violet irradiation. It is likely that as the surface cracked, voids appeared at the surface of the WPC samples of polyvinyl chloride interface and the overall density of composite decreased.

Table 5: The morphological test result for the WPC sample upon UV irradiation exposure (Polyvinyl Chloride) with a magnification of $50 \mu \mathrm{m}$ and $100 \mu \mathrm{m}$.

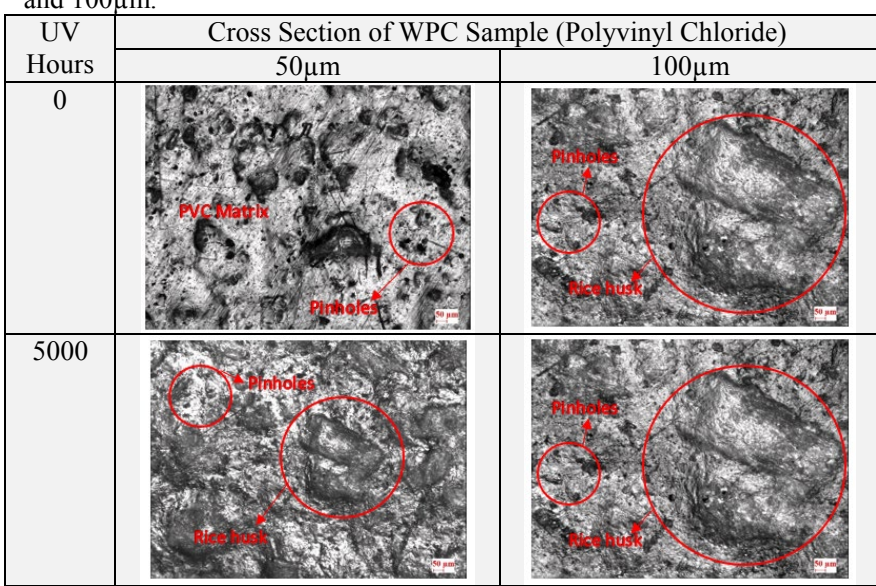

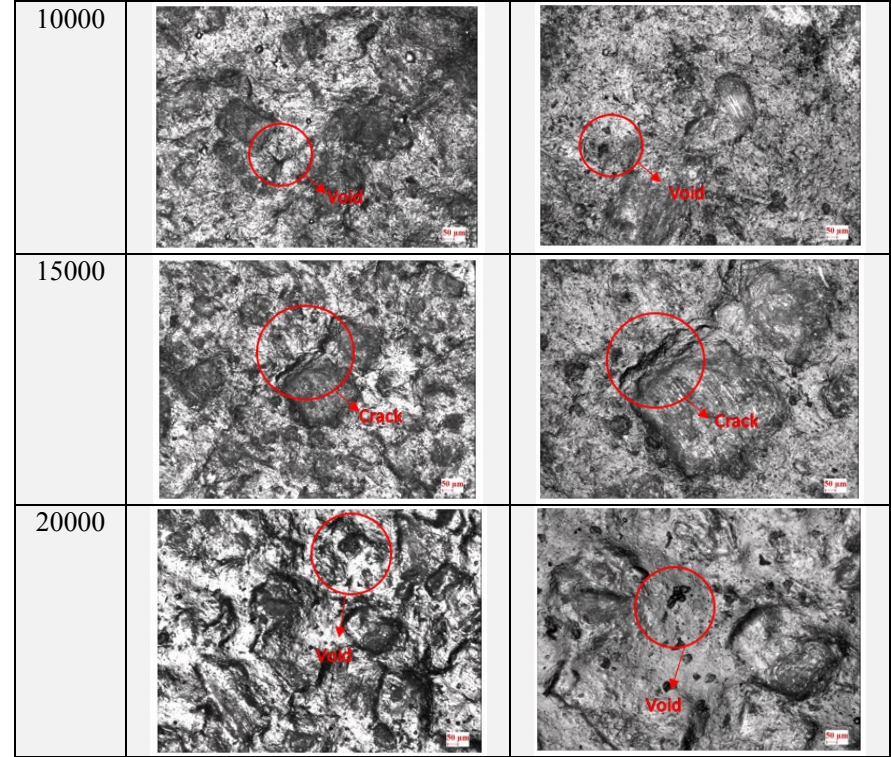

The different morphologies of the surface layers of the composites weathered under accelerated ultra violet irradiation exposure condition can be explained by the prevailing influence of different weathering factors. As noted above, in the case of accelerated weathering, the sole weathering factor was ultra violet irradiation and photo-degradation was the mechanism which led to the disappearance of the polymer surface layer.

The WPC samples of polypropylene been undergo an ultra violet irradiation exposure from a 5000 hours until 20,000 hours, the surface morphology of the composites had changed drastically. The surface layer has disintegrated: numerous cracks in the matrix can be seen. Wood particles are separated from a part of the matrix. The polypropylene photo degradation and wood particles shrinking can cause cracks on the surface of composites.

The density of the polypropylene samples been decreased. This is consistent with the surface degradation (surface cracks and voids) obtained by the Optical Microscopy from the 5000 hours until 20,000 hours ultra violet irradiation. It is likely that as the surface cracked, voids appeared at the surface of the WPC samples of polypropylene interface and the overall density of composite decreased.

Table 6: The morphological test result for the WPC sample upon UV irradiation exposure (Polypropylene) with a magnification of $50 \mu \mathrm{m}$ and $100 \mu \mathrm{m}$

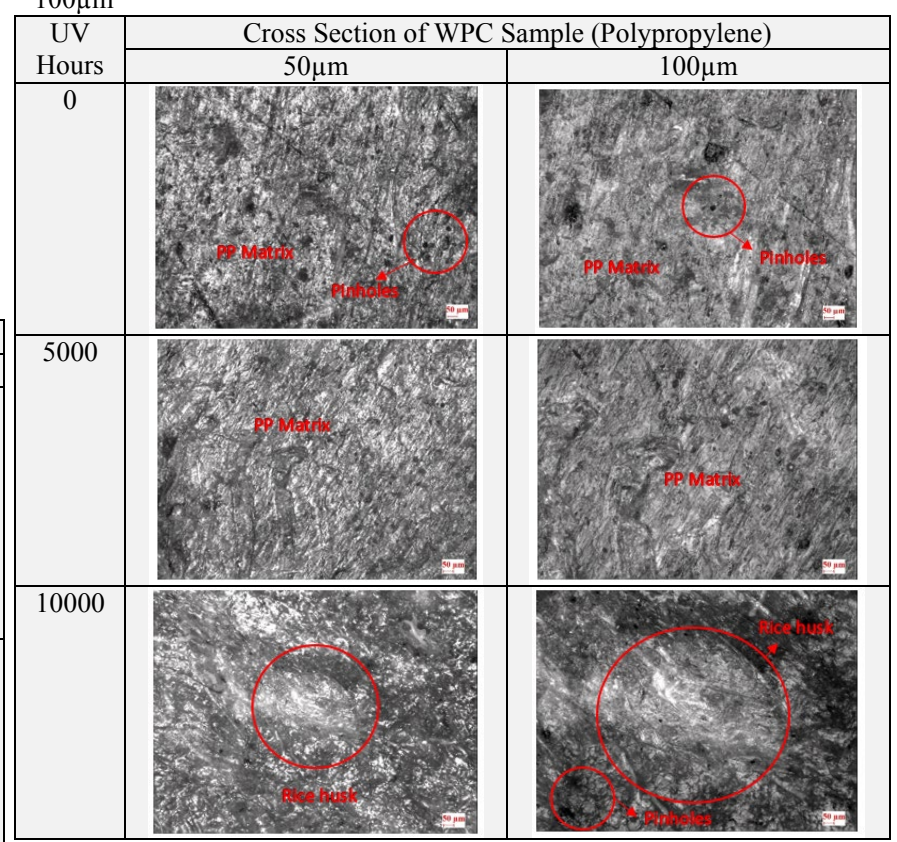




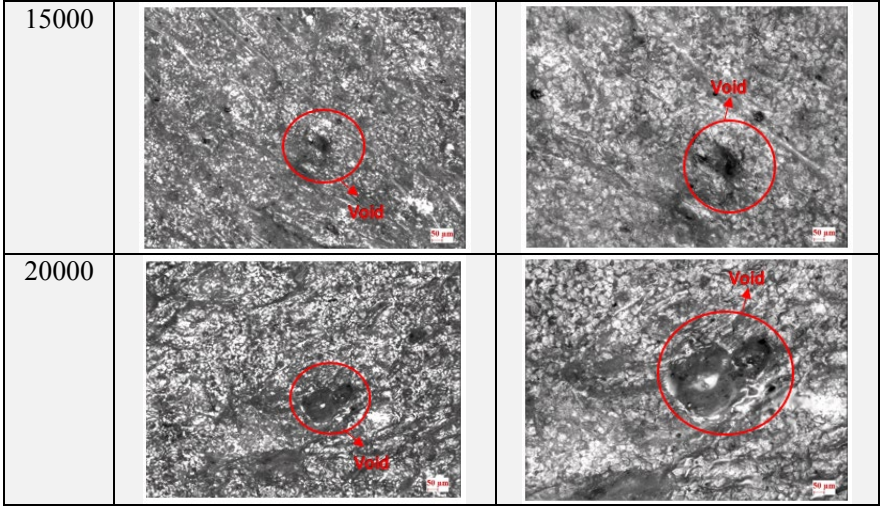

\section{Conclusion}

In conclusion, the objectives of this research was achieved with the samples of wood polymer composites have been successfully prepared with specific size for the density test, morphological surface analysis and also dynamic mechanical analysis $(\tan \delta$ ) before and after ultra violet irradiation exposure.

Mechanical properties of the WPC sample of PVC and PP upon ultra violet irradiation exposure at the same time have been studied and analysed. The result revealed for the WPC sample of PVC, it can be easily seen that the value of storage modulus (E') decreases when been exposed in the ultra violet irradiation in both glassy and rubbery states. The highest value of PVC storage modulus is $59.3633 \mathrm{MPa}$ for the un-irradiated sample at 0 hours ultra violet exposure with the value of crosslink density of $6.5646 \mathrm{M} / \mathrm{m}^{3}$. For the WPC sample of PP, highest value of storage modulus is 199.0370 MPa for the un-irradiated sample at 0 hours ultra violet exposure with the value of crosslink density of $20.957 \mathrm{M} / \mathrm{m}^{3}$.

From the result of WPC sample of PVC, it can be observed that the maximum value of loss modulus (E") for the WPC samples for un-irradiated sample is higher than the samples that been ultra violet exposed until 20,000 hours and also revealed the same trend for PP. For the WPC sample of PVC, $\tan \delta$, it is very evident that the glass transition temperature $\mathrm{Tg}$, determined by the value of tan $\delta$ peak maximum. The highest value of $\tan \delta$ is 0.5850 for the sample of 20,000 hours ultra violet irradiation exposure. The highest value of $\tan \delta$ for WPC sample of PP is 0.1521 for the unirradiated WPC sample or 0 hours ultra violet irradiation exposure.

\section{Acknowledgement}

The authors would like to acknowledge the Sustainable Polymer Engineering, Advanced Manufacturing and Material Center (SPEN-AMMC), Faculty of Mechanical and Manufacturing Engineering (FKMP) Universiti Tun Hussein Onn Malaysia (UTHM) Malaysi and Malaysian Government Fundamental Research Grant Scheme (FRGS Phase 1/2015) Vot 1534.

\section{References}

[1] Anuar, H., \& Ahmad, Z. (2011). Thermal properties of injection moulded polylactic acid - Kenaf fibre biocomposite. Malaysian Polymer Journal, 6(1), 51-57.

[2] Arjmandi, R., Hassan, A., Majeed, K., \& Zakaria, Z. (2015). Rice husk filled polymer composites. International Journal of Polymer Science, 2015, 1-32.

[3] Bakar, N. A., Chee, C. Y., Abdullah, L. C., Ratnam, C. T., \& Ibrahim, N. A. (2015). Thermal and dynamic mechanical properties of grafted kenaf filled poly (vinyl chloride)/ethylene vinyl acetate composites. Materials and Design, 65, 204-211.

[4] Beyler, C. L., \& Hirschler, M. M. (2001). Thermal decomposition of polymers. In M. J. Hurley, D. T. Gottuk, J. R. Hall Jr., K. Harada, E. D. Kuligowski, M. Puchovsky, J. L. Torero, J. M. Watts
Jr., \& C. J. Wieczorek, (Eds.), SPE Handbook of Fire Protection Engineering. Berlin: Springer Verlag, pp. 110-131.

[5] Bourne, P. J. (2007). Evaluation of rice hulls as a lignocellulosic substitute in wood plastic composites. Inquiry: The University of Arkansas Undergraduate Research Journal, 7(2), 66-72.

[6] Carlsson, K. (2007). Light microscopy. Stockholm: KTH Physics.

[7] Chen, R. S., Ab Ghani, M. H., Salleh, M. N., Ahmad, S., \& Tarawneh, M. A. (2015). Mechanical, water absorption, and morphology of recycled polymer blend rice husk flour biocomposites. Journal of Applied Polymer Science, 132(8), 1-12.

[8] Chuah, T. G., Jumasiah, A., Azni, I., Katayon, S., \& Thomas Choong, S. Y. (2005). Rice husk as a potentially low-cost biosorbent for heavy metal and dye removal: An overview. Desalination, 175(3), 305-316.

[9] Dez-Gutirrez, S., Rodrguez-Prez, M. A., De Saja, J. A., \& Velasco, J. I. (1999). Dynamic mechanical analysis of injection-moulded discs of polypropylene and untreated and silane-treated talc-filled polypropylene composites. Polymer, 40(19), 5345-5353.

[10] Dukarska, D., Czarnecki, R., Dziurka, D., \& Mirski, R. (2017). Construction particleboards made from rapeseed straw glued with hybrid pMDI / PF resin. European Journal of Wood and Wood Products, 75(2), 175-184.

[11] Gardner, D. J., Han, Y., \& Wang, L. (2015). Wood-plastic composite technology. Current Forestry Reports, 1(3), 139-150.

[12] Göpferich, A. (1996). Mechanisms of polymer degradation and erosion. Biomaterials, 17(2), 103-114.

[13] Jais, F. H. M., Omar, N. A. A., \& Rus, A. Z. M. (2016). Photostability characterization of wood polymer composites of polyvinyl chloride and rice husk to ultra-violet irradiation exposure. MATEC Web of Conferences, 78, 1-5.

[14] Kamweru, P. K., Ndiritu, F. G., Kinyanjui, T., Muthui, Z. W., \& Gichuki, R. (2014). UV Absorption and dynamic mechanical analysis of polyethylene films. International Journal of Physical Sciences, 9(24), 545-555.

[15] Maddah, H. A. (2016). Polypropylene as a promising plastic: A review. American Journal of Polymer Science, 6(1), 1-11. 